\title{
LA NOVELA DE HUMOR Y LA CENSURA: EL CASO JARDIEL PONCELA
}

Juan Carlos PUEO

Universidad de Zaragoza

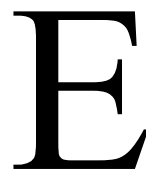

n La «tournée» de Dios — la última novela del ciclo que escribió para la editorial Biblioteca Nueva, publicada en 1932 - Jardiel hace declarar al Supremo Hacedor: «LA FORMA IDEAL DE GOBIERNO EN LOS ESTADOS DE LA TIERRA SON LAS DICTADURAS. PARA GOBERNAR NO HAY MÁS QUE UN CAMINO: QUE UN SOLO HOMBRE INTELIGENTE CREE AL MISMO TIEMPO UNA LEY JUSTA Y UNA PENA TERRIBLE. Y, TRANSGREDIDA LA LEY, APLIQUE LA PENA SIN APELACIÓN, SIN INDULTO Y POR LA ETERNIDAD» (Jardiel Poncela, 1932: 306). Como ha señalado la crítica en numerosas ocasiones, el Dios de la novela de Jardiel se halla más cercano al Dios vengador del Antiguo Testamento que al misericordioso del Nuevo. Y es este Dios el que elige Jardiel para formular a través de él todo su ideario político, religioso y vital. Sabido es que la actitud política de Jardiel tendía a un individualismo de signo reaccionario, y aunque es verdad que los episodios transcurridos durante la Guerra Civil - confiscación de su automóvil por un grupo de milicianos, interrogatorio en una checa con motivo de una delación que le acusaba de ocultar a un político de derechas, profanación de la tumba de su madre en Quinto de Ebro - le llevaron a escapar de la zona republicana, su postura respecto al bando de los sublevados fue desde el primer momento de simpatía: en las primeras semanas, cuando todavía esperaba que el ejército franquista tomase Madrid sin problemas, se ofreció para esconder a su amigo Carlos Sampelayo, periodista del Heraldo de Madrid que se había significado claramente a favor de la causa republicana ${ }^{1}$. Los acontecimientos se sucedieron de forma distinta, y Jardiel se vio obligado a escapar de la capital. Pero cuando, después de haber pasado por Francia y Argentina, se apresuró a volver a la zona llamada nacional, lo hizo con la esperanza de no tener ningún problema para reanudar su labor literaria.

\footnotetext{
1 «Parece claro, pues, que la radicalización de Jardiel Poncela después de la Guerra Civil no obedece exclusivamente a los motivos viscerales anteriormente expuestos, ni tampoco a su súbita identificación con la figura de Franco y con la trayectoria política que desarrolla en España; sino que se limita a catalizar un sustrato ideológico que siempre estuvo latente en su pensamiento y en su obra, y del que [La "tournée" de Dios] es un claro exponente. Su escepticismo político, que lo conduce frecuentemente a posturas extremas de carácter anárquico y destructivo, se manifiesta a lo largo de toda su carrera literaria posterior y anterior a la Guerra Civil, y su expresa repulsa al Socialismo y al Comunismo son constantes en su literatura, descargando a través de ella la virulencia de su humor» (Alemany, 1989: 43).
} 
A tenor de la opinión citada, en la que se hace patente la preferencia de Jardiel por los gobiernos totalitarios, podría pensarse que el régimen franquista estaría encantado con la obra de este autor, claramente afecto al régimen ${ }^{2}$. Sin embargo, no fue así. Si en el terreno político comulgaba con los principios fundamentales del movimiento, no ocurría lo mismo en lo que se refiere a las cuestiones morales y religiosas en las que éste se apoyaba. En su práctica teatral, dirigida a un público amplio para el que no resultaban aceptables desahogos de ningún tipo respecto a la moral y a la religión oficiales, Jardiel tuvo que seguir practicando la autocensura que se había impuesto desde los comienzos de su carrera teatral en solitario - tras sus colaboraciones con Serafín Adame-. Pero la narrativa presentaba un problema mayor, pues Jardiel se veía más libre para escribir a un público con el que se sentía en sintonía $^{3}$ y con el que podía sincerarse en aquellas cuestiones que se veía obligado a callar cuando escribía teatro. Ahora bien, las libertades que en materia de moral y religión se tomó nuestro autor entre 1929 y 1932, años en los que publicó sus cuatro novelas grandes, resultaban inadmisibles en 1939, cuando la editorial Biblioteca Nueva se propuso reeditarlas. La censura dictaminó sobre la primera de ellas, Amor se escribe sin hache:

El ambiente total de la obra sin ser grosero es de una inmoralidad continua adobada con la gracia y el humor peculiar del autor. Esta novela podría ser reeditada en el momento actual si el mismo autor con su inteligencia ya probada la adaptara al ambiente y vida española del momento presente. Podría quedar una novela de humor apreciable, aunque la empresa no es fácil y por ello debe hacerla el autor. ${ }^{4}$

Jardiel no tuvo más remedio que revisar la novela y eliminar de ella todos los elementos inmorales. Ya lo había hecho antes con las novelas ¡Espérame en Siberia, vida mía! y Pero... ¿hubo alguna vez once mil vírgenes?, cuyos ejemplares autocensurados pudo estudiar Manuel M. Abellán ${ }^{5}$. La «tournée» de Dios, en cambio, no podía reeditarse: no sólo porque los elementos de inmoralidad

\footnotetext{
${ }^{2}$ Por si todavía hay quien duda de esta afección, compatible, no obstante, con su individualismo antipartidista, he aquí las propias palabras de Jardiel: «Contra la "acusación” de falangista, me hubiera bastado con decir — como era y sigue siendo la verdad - que yo no he pertenecido nunca a Falange; contra la acusación de partidario de Franco, me hubiera bastado, también, con decir que partidario era poco decir; que yo con respecto a Franco siento algo mucho más profundo: siento idénticos sentimientos con respecto a España; pues Franco y España son sinónimos y significan lo mismo para todo buen español, puesto que sin Franco, España hubiera muerto en el verano de 1936 y hoy España sería una república soviética: ésta es también la verdad, aunque los traidores a España no quieran confesárselo así; y contra las acusaciones de que yo había llamado en una ocasión "memocracia" a la democracia que hubo en España, yo jamás hubiera dicho de ella una cosa tan vulgar y tan amable: lo menos que la hubiera llamado hubiera sido "asesinocracia", que es lo que fue, mientras imperó a sus anchas en Madrid, Barcelona, etc., desde febrero de 1936 en que subió al poder esa "democracia española" (?) hasta el 28 de marzo de 1939 en que las tropas de Franco entraron triunfantes en Madrid, iniciando el principio del fin de la guerra española» (Jardiel Poncela, 1950: 238-239; en cursiva en el texto).

3 «Para mí, escribir Novela es un goce, y escribir Teatro, una preocupación. La Novela va dirigida a un público limitado, que sabe quién es uno, que le busca a uno y que, frecuentemente, le quiere a uno; hacer Novela es hablar a gentes que comprenden, estiman, respetan y admiran. El Teatro, por el contrario, va dirigido a una masa heterogénea, sin seleccionar y refinar, que, en el 80 por 100 de los casos, no conoce al autor ni le importa de él lo más mínimo. Esa masa heterogénea, a menudo sin civilizar, rara vez admira ni siente afecto por el escritor y jamás le respeta» (Jardiel Poncela, 1934: 244-245). ${ }^{4}$ Servicio Nacional de Propaganda, Departamento de Censura de Libros, expediente J-312 (30-11-1939).

5 «La recuperación de dos ejemplares modificados de la propia mano de Jardiel Poncela no deja ningún lugar a dudas acerca de la habilidad del escritor para modificar el texto de sus novelas con enjundia y sorna, si bien las tachaduras tuvieron una extensión espeluznante. Véase: de las 315 páginas de texto que comprendía la novela ¿Pero... hubo alguna vez once mil vírgenes? el escritor autocensuró 218. La mayoría de estas tachaduras se refiere, como es natural, a problemas de lenguaje relacionados con la moral sexual. A veces se sustituye una palabra por otra» (Abellán, 1980: 20).
} 
fueran mucho más fuertes, si bien eran menores en número, sino porque las tesis religiosas atacaban directamente los dogmas religiosos o dejaban en ridículo a los fieles, comenzando por el mismísimo Papa $^{6}$. Ahora bien, la autocensura de Jardiel a sus tres primeras novelas no se limitó a eliminar los elementos de inmoralidad - los cuales no sólo incluyen las alusiones al sexo, sino también las referencias al cristianismo- - sino que se curó en salud en lo que se refiere a la política, suprimiendo no sólo las referencias a personajes destacados de la República, sino también las alusiones humorísticas a italianos y alemanes. Como todo el mundo sabe, en 1939 la cosa no estaba para bromas.

A pesar de haber sido expurgadas, las novelas tuvieron el mismo éxito que habían tenido en los años treinta, si bien los ejemplares de segunda mano de las ediciones previas a la guerra se vendían —clandestinamente, eso sí- mucho mejor. Quizás fue por esta razón por lo que en 1940 la censura retiró su visto bueno para las nuevas ediciones de ¡Espérame en Siberia, vida mía! y Pero... ¿hubo alguna vez once mil vírgenes?, y prohibió en 1942 que la editorial Biblioteca Nueva siguiera vendiendo los ejemplares que quedaban de Amor se escribe sin hache. La prohibición se levantaría en 1946, bajo la condición de que la siguiente edición de la novela fuese nuevamente expurgada, lo que frenó el proyecto de reedición ${ }^{7}$. Así, ninguna de las cuatro novelas se volvió a publicar, permaneciendo prohibidas por la censura por lo menos hasta $1958^{8}$. El argumento que se adujo fue el de que, a pesar de haber desaparecido todas las referencias a la religión o a la política, no ocurría lo mismo con la temática erótica, que resultaba todavía demasiado inmoral. No obstante, el problema no era la presunta inmoralidad que permanecía en los textos expurgados: aunque los retoques afectaron de forma evidente al contenido de las tres novelas — centradas en las relaciones amorosas de sus protagonistas-, Jardiel pudo suprimir los pasajes más problemáticos y mantener la coherencia de los textos, que perdieron buena parte, pero no toda su fuerza, ya que no se trataba tanto de relatos eróticos como de relatos humorísticos ${ }^{9}$. ¿Por qué fueron entonces prohibidas estas novelas? Aquí es donde se impone una reflexión — si bien quedará limitada por el objeto al que se refiere — sobre la función y el alcance de la censura aplicada al humor.

\footnotetext{
${ }^{6}$ Valgan algunos ejemplos: en la entrevista que concede Dios al periodista Perico Espasa, no sólo declara su preferencia por los gobiernos totalitarios, sino que sanciona nociones como la pluralidad de los mundos o la evolución, y muestra su desacuerdo con las doctrinas de Jesucristo. En cuanto al ataque a los fieles, Dios se burla constantemente de las muestras de adoración que recibe allá donde va. El colmo de la irreverencia tiene lugar cuando el narrador explica que el Papa sufría una depresión porque la presencia de Dios le quitaba protagonismo.

${ }^{7}$ Para un relato más extenso de los problemas de Jardiel con la censura, véase Pueo (2016: passim).

${ }^{8}$ Ese año vuelven a aparecer en la primera edición de las Obras completas de Enrique Jardiel Poncela, editadas, sin embargo, en México. Estas Obras completas se reeditaron en España varias veces a lo largo de los años sesenta, y la misma editorial (AHR) publicó las cuatro novelas por separado en 1965 y 1968, lo que prueba el favor del que siguieron gozando. La razón de esta permisividad se halla en que se trataba de ediciones de lujo, asequibles únicamente para lectores de clase acomodada sin problemas económicos, y difícilmente accesibles para las clases populares.

${ }^{9}$ «[El erotismo] ni siquiera llega a ser tema dominante, aunque constituya el trasfondo último de sus tres primeras novelas. En cualquier caso, dosis de erotismo, burla de la novela amorosa, parodia, lucha contra el tópico, pero todo ello desde la perspectiva del humor. De un humor que rebasaba, en su época, todos los límites no ya permitidos, sino incluso imaginables por el lector. Un humor que afecta desde la estructura y construcción de la novela hasta la caracterización de los personajes. Desde las historias narradas hasta la sintaxis de la narración, desde la distorsión del concepto hasta la expresión gráfica del mismo. Un humor que posibilita el distanciamiento crítico del lector, sin que éste pierda el sentido último de la narración. Para ello las dosis de erotismo están sabiamente distribuidas a lo largo del texto, de manera que el lector nunca llegue a cebarse excesivamente en él» (Pérez, 1990: 23-24).
} 
La censura es, ante todo, un procedimiento disciplinario. Aquellos elementos de un tex to que no son tolerados por el régimen censor pueden acabar siendo objeto de una condena penal ${ }^{10}$, bajo el pretexto de que el escritor ha infringido la ley que le prohibía atentar contra el orden público. Es decir, el escritor se ha situado al otro lado de la ley negando su legitimidad para ubicarle a él en el lado de los buenos cuando la respeta y en el de los malos cuando la quebranta. Es este posicionamiento del autor el que la censura previa pretende conjurar, logrando evitar también que su obra se publique —en el sentido de «dar a conocer al público»— y caiga en manos inocentes e incluso culpables que puedan comprobar que existe la posibilidad de posicionarse en contra de la ley. El caso del humorista es distinto, porque lo que se propone no es negar la capacidad de la ley para colocarle dentro o fuera de la legitimidad, sino soslayar esta capacidad situándose en el margen. Conviene hacer algunas matizaciones, porque la risa puede llevar consigo un posicionamiento contrario a la ley: en ciertas formas - la sátira, por ejemplo-, la actitud del satírico es abiertamente hostil hacia su objetivo, y actúa mediante la ridiculización que, en definitiva, acaba considerándose un ataque contra el honor de dicho objetivo, y, por tanto, un delito. Pero este no es el caso del humorismo, que no se plantea como ataque hacia la ley, sino como una forma de sortearla.

El caso de las novelas de Jardiel es paradigmático. Evidentemente, la presencia de elementos eróticos, religiosos y políticos tenía que molestar a las autoridades censoras, pero dichos elementos eran, como ya he señalado, secundarios, y Jardiel podía prescindir de ellos sin demasiados problemas: en ¡Espérame en Siberia, vida mía!, el único personaje que aparece caracterizado positivamente es un oso amaestrado capaz de hablar y de razonar mucho mejor que los restantes personajes de la novela. En la edición de 1930, el oso recibe el nombre de Mussolini, que, en 1939 hubo de ser cambiado, por motivos obvios, al de Paganini, sin que el cambio perjudicase de ninguna manera al resto de la novela. Las razones son evidentes, pero hay que hacer constar que la única razón por la que el oso recibe el nombre del dictador es su nacionalidad italiana — quizás también su constitución física-, ya que ninguna de sus intervenciones tiene carácter satírico ${ }^{11}$ : es decir, en ningún momento se hace al oso Mussolini portavoz de la ideología fascista, ni se le relaciona con ella con intención de ridiculizarla. Tampoco puede decirse que la caracterización positiva del oso —que es un personaje encantador-

\footnotetext{
${ }^{10}$ Lo cual no deja de ser otra forma de censura, aunque en este caso no es previa, sino posterior. Ahora bien, se trata de dos formas de actuación completamente diferentes, como recuerda Román Gubern: «los juristas norteamericanos Thomas B. Leary y Roger Noall [...] estudiaron la radical diferencia entre el control previo de un mensaje antes de que tenga lugar su difusión pública (censura previa) y las sanciones subsiguientes que penalizan a aquellos que han difundido mensajes objetables. El primer control constituye la censura previa ejercida usualmente por el poder ejecutivo, mientras que la segunda se refiere por lo regular a la acción judicial ejercida sobre mensajes que presuntamente violan alguna forma del ordenamiento penal. Ambas modalidades censoras son muy diferentes [...]. La corriente de pensamiento liberal atribuye por lo general mayor equidad y ventajas al control ejercido por el poder judicial. Entre otras garantías se señalan la presunción de inocencia del acusado y que la carga de la prueba recaiga sobre el ministerio fiscal» (Gubern, 1981: 10-11). ${ }^{11}$ Esta ausencia de motivaciones satíricas —en el sentido de emplear la risa con intención crítica- es una constante en la obra de Jardiel y la de otros autores de su generación como Mihura, Neville o López Rubio, todos ellos situados en la órbita de Ramón Gómez de la Serna, como ya vio Guillermo Díaz-Plaja con motivo de la publicación de Pero... ¿hubo alguna vez once mil vírgenes?: «Cuando el humorismo ha dejado de ser una reacción cínica ante el sentimentalismo —es decir, cuando lo sentimental ha dejado de cotizar en la literatura y su reversión al humour no ha tenido valor de sátira-, el imperativo de risa se ha encauzado hacia un nuevo humorismo de desenfado verbal e imagen descoyuntada cuyo origen habría que buscar, para España, en la obra de Ramón Gómez de la Serna» (Díaz-Plaja, 1931).
} 
responda a una intención laudatoria respecto al dictador, porque, al fin y al cabo, sigue siendo un oso, y asociar el personaje ficticio con el real no puede considerarse sino una forma de rebajar al segundo, y a todo lo que significa.

Este ejemplo revela la ambigüedad con la que actúa el humorismo, ambigüedad ante la que la censura no podía sentirse cómoda. En el caso del nombre de Mussolini era evidente la necesidad de cambiarlo por el más inocente de Paganini, pero no ocurría lo mismo con otras cuestiones más inocentes, donde la ausencia de motivos estrictamente satíricos situaba al humorista en un territorio impreciso, máxime cuando se trataba de un autor cuya ideología se identificaba de forma entusiasta con el régimen franquista: así, sólo podía ser acusado de inadvertencia al tomar como motivos humorísticos ciertos elementos políticos o religiosos - ya que se ponía en peligro de ridiculizarlos-, o eróticos - ya que se ponía en peligro de exaltarlos ${ }^{12}$ - Esta peligrosa ambigüedad es resultado de la posición marginal en la que se sitúa el humorista, una posición que no puede ser prohibida, pero que ha de ser vigilada constantemente. En este sentido, el humorismo es objeto de la misma actitud preventiva que se aplica a las obras que, aunque no se sitúen fuera de la ley, tampoco se dedican a defender aquellos principios cuya pureza hay que custodiar. Hay que vigilar que la presunta neutralidad del autor no produzca ningún tipo de contraste con la imagen oficial del régimen. Incluso cuando se coloca en posiciones abiertamente afines a las de éste, el autor es objeto de una vigilancia estricta que lleva al censor a redactar siempre un informe donde se destaca si ha de rectificar los pasajes de su obra que atentan contra las reglas establecidas ${ }^{13}$.

Así pues, la censura actúa porque considera que necesita controlar aquellas actitudes que puedan salirse de lo normativo, entendido no sólo como «la norma», sino también como «lo normal». Al igual que cualquier otro procedimiento disciplinario, la censura previa tiene como misión corregir al individuo para que no se salga de la norma, para que, mediante las correcciones impuestas, se ejercite en el cumplimiento de la ley que, en este caso, le premia con el permiso de publicación por escribir aquello que está permitido ${ }^{14}$. Porque, como señala Michel Foucault, la corrección disciplinaria se aplica a los niños, a los enfermos, a los locos y a los delincuentes, es decir, aquéllos a quienes, por una razón o por otra, no se les considera «normales» y han de ser objeto de un proceso de corrección. El autor censurado no es muy diferente — de hecho, si llega a publicar su texto sin respetar las

\footnotetext{
12 Prueba de ello es el hecho de que las novelas de Jardiel, a pesar de ser novelas de humor, habían sido leídas en muchos casos por su erotismo. Recordaba Ramón Gómez de la Serna (1958: 981) que «en las ciudades con academia militar [sus novelas] se vendían más rápidamente que en las otras». Esta ambigüedad es efecto natural del carácter paródico de las novelas de Jardiel, cuyo modelo eran las novelas eróticas serias de Alberto Insúa, Pedro Mata, Eduardo Zamacois, Antonio Hoyos y Vinet, etc.

13 «El punto ideal de la penalidad hoy día sería la disciplina indefinida: un interrogatorio que no tuviera término, una investigación que se prolongara sin límite en una observación minuciosa y cada vez más analítica, un juicio que fuese al mismo tiempo la constitución de un expediente jamás cerrado, la benignidad calculada de una pena que estaría entrelazada a la curiosidad encarnizada de un examen, un procedimiento que fuera a la vez la medida permanente de una desviación respecto de una norma inaccesible y el movimiento asintónico que obliga a coincidir con ella en el infinito» (Foucault, 1975: 328).

14 «El castigo disciplinario es, en una buena parte al menos, isomorfo a la obligación misma; es menos la venganza de la ley ultrajada que su repetición, su insistencia redoblada. Tanto el efecto correctivo que se espera no pasa sino de una manera accesoria por la expiación y al arrepentimiento; se obtienen directamente por el mecanismo de un encauzamiento de la conducta. Castigar es ejercitar» (Foucault, 1975: 268).
} 
indicaciones de la censura, pasa a ser un delincuente y es objeto de un proceso penalprevia es el procedimiento empleado para reconocer a los autores que pertenecen al grupo de los «desplazados» de la sociedad, los que se salen de lo normal, los individualizados gracias a su desobediencia a la normalidad vigente ${ }^{15}$. Y, asimismo, la censura es el procedimiento ideal para reconducirlos por el buen camino y hacer de ellos ciudadanos convencionales, anodinos y, por tanto, inocuos.

Si esto es patente en el caso de los autores que plantean posiciones críticas desde un punto de vista serio, no lo es menos en el caso de los que lo hacen desde planteamientos humorísticos. Sin embargo, hay una diferencia importante, porque, como hemos visto, el humor no se enfrenta a la ley, sino que la soslaya. Más aún, el humorismo no pretende acabar con la ley para sustituirla por otra — quizás más justa—, sino situarse en la frontera del territorio de la ley, lo cual refuerza su ambigüedad: porque no cuestiona su pertinencia, pero, al mismo tiempo, niega su necesidad ${ }^{16}$. Por eso el humorista no puede asimilarse al delincuente, sino al niño o al loco, cuyas vidas no están contra la ley, sino al margen de ella. Ahora bien, existe un límite para todos ellos: al niño y al loco podemos reírles las gracias siempre que el espíritu de la ley no se vea alterado por su conducta, en cuyo caso es necesario reprimirla; hay que hacerles conocer la ley y la necesidad de cumplirla. El niño varón puede usar una barra de carmín para disfrazarse de indio, pero no para pintarse los labios, incluso cuando ambas cosas puedan provocar la risa. Es decir, al niño se le permite salirse de la ley en circunstancias especiales y sólo cuando la transgresión no rompe la ley y, por tanto, no tiene consecuencias. Lo mismo ocurre con el loco, que es encerrado cuando se considera que su conducta puede ser perjudicial para los cuerdos. Claro está que al humorista no se le considera de la misma manera que al niño o al loco, a quienes, en definitiva, no se considera responsables de sus transgresiones. No obstante, el humorista es sometido por la censura a una vigilancia similar a la que ejercen los maestros o los psiquiatras: se le permite ignorar la ley, siempre que no la transgreda. De ahí el debate acerca de la licitud de la risa: mientras que unos le niegan toda capacidad crítica y sospechan que en realidad sirve de refuerzo a la ley, otros ven en ella una poderosa fuerza subversiva que, en vez de acabar con lo superficial, dinamita las bases de todas las magnitudes culturales.

\footnotetext{
15 «En un régimen disciplinario, la individualización es en cambio "descendente": a medida que el poder se vuelve más anónimo y más funcional, aquellos sobre los que se ejerce tienden a estar más fuertemente individualizados; y por vigilancias más que por ceremonias, por observaciones más que por relatos conmemorativos, por medidas comparativas que tienen la "norma" por referencia, y no por genealogías que dan los antepasados como puntos de mira; por “desviaciones" más que por hechos señalados. En un sistema de disciplina, el niño está más individualizado que el adulto, el enfermo más que el hombre sano, el loco y el delincuente más que el normal y el no delincuente. En todo caso, es hacia los primeros a los que se dirigen en nuestra civilización todos los mecanismos individualizantes; y cuando se quiere individualizar al adulto sano, normal y legalista, es siempre buscando lo que hay en él todavía de niño, la locura secreta que lo habita, el crimen fundamental que ha querido cometer» (Foucault, 1975: 285).

16 «El humor no pretende, como el carnaval, llevarnos más allá de nuestros propios límites. Nos da la sensación, o más bien el diseño de la estructura de nuestros propios límites. Nunca está fuera de los límites, sino que mina los límites desde dentro. No busca una libertad imposible, pero es un verdadero movimiento de libertad. El humor no nos promete liberación: al contrario, nos advierte la imposibilidad de una liberación global, recordándonos la presencia de una ley que ya no hay razón para obedecer. Al hacerlo, mina la ley. Nos hace sentir la molestia de vivir bajo una ley, cualquier ley» (Eco, 1984: 19).
} 
Si el humorista ha de ser vigilado es porque en él la inocencia es un disfraz que puede servirle para ocultar sus verdaderas intenciones. Ignorar la ley puede ser una forma de enfrentarse a ella, quizás la única forma cuando la represión es tan feroz que no permite otra forma de disidencia, que, paradójicamente, es propiciada por la existencia de la propia censura: sabido es que si la represión censora lleva a muchos autores a mantenerse en los límites de lo tolerado, también da pie a otros a buscar todo tipo de mecanismos que le permitan esquivarla ${ }^{17}$. Y el humor no es precisamente una de las formas menos importantes de eludir al censor: no tanto porque permita ocultar la crítica bajo la sátira sino porque, como dice Ramón Gómez de la Serna, «el humor abaja las alcurnias y hace soportable el hecho de la autoridad» (1930: 454). Por esta razón, el humor sólo se permite cuando se presenta como un desahogo, un paréntesis tras el cual la seriedad volverá a tomar las riendas. Pero cuando el humor se convierte en una postura continuada, en un enfoque que no reconoce la primacía de la perspectiva seria, termina resultando una compañía molesta. Esto lo han sabido todos los regímenes totalitarios, que se han empeñado en acotar la risa haciendo que sólo sirviera a sus propios fines.

El humorismo de Jardiel resultaba demasiado perturbador, puesto que se permitía el lujo, en una época donde los valores estaban rígidamente clasificados, de medir con el mismo rasero cualquier elemento de la civilización, desde las normas de la gramática a los grupos de poder. Precisamente porque cualquier concepto es susceptible de ser intelectualmente dislocado ${ }^{18}$ es por lo que el censor de Amor se escribe sin hache no vio ninguna dificultad para que Jardiel siguiera practicando su particular forma de entender el humor, una vez se hubiesen pulido aquellos elementos que, sin haberlo querido, atentaban contra el nuevo orden. Pero el censor no se daba cuenta de que no era suficiente con pulir las novelas. El humorismo de Jardiel seguía causando incomodidad, y puede que fuera ésta la auténtica razón —-más allá de su erotismo - por la que sus novelas fueron posteriormente prohibidas. El final de la historia apunta a esta conclusión: Jardiel no volvió a escribir novelas y se dedicó por completo al

\footnotetext{
17 «La censura inhibe la comunicación, pero también estimula a la imaginación a buscar la forma de burlarla. Con otras palabras: es precisamente la prohibición lo que incita a la imaginación a oponerse a la prohibición; es precisamente el intento de eludir la censura el que produce obras maestras» (Neuschäfer, 1991: 56).

${ }^{18}$ La dislocación intelectual es una constante de la vanguardia, con la que el humorismo de Gómez de la Serna y Jardiel mantuvo contactos que han sido continuamente señalados por la crítica, ya desde Ortega y Gasset: «Uno [de los intrumentos de deshumanización], el más simple, consiste en un simple cambio de la perspectiva habitual. Desde el punto de vista humano tienen las cosas un solo orden, una jerarquía determinados. Nos parecen unas muy importantes, otras menos, otras por completo insignificantes. Para satisfacer el ansia de deshumanizar no es, pues, forzoso alterar las formas primarias de las cosas. Basta con invertir la jerarquía y hacer un arte donde aparezcan en primer plano, destacados con aire monumental, los mínimos sucesos de la vida» (Ortega y Gasset, 1925: 38). Y, más adelante: «Ahora bien, no puede menos de extrañar a quien para en ello mientes que la nueva inspiración es siempre, indefectiblemente, cómica. Toda ella suena en esa sola cuerda y tono. La comicidad será más o menos violenta y correrá desde la franca "clownería” hasta el leve guiño irónico, pero no falta nunca. Y no es que el contenido de la obra sea cómico — esto sería recaer en un modo o categoría del estilo "humano"- , sino que, sea cual fuere el contenido, el arte mismo se hace broma. Buscar, como antes he indicado, la ficción como tal ficción es propósito que no puede tenerse sino en un estado de alma jovial. Se va al arte precisamente porque se le reconoce como farsa» (48). Esto es especialmente relevante en el caso de la novela, que en los años veinte se había caracterizado por su voluntad de violentar los esquemas básicos de la representación narrativa clásica: «Una segunda vía de renovación es la que afecta al proceso de imitatio, reproducción o figuración de la realidad en la novela, y trata o manipula la realidad externa mediante sistemas que la distorsionan o destruyen en el texto. La vía más importante es el esperpento; sin embargo, no es única. El humor, el distanciamiento interpretativo de la realidad, básicamente intelectual, es otro procedimiento para "desrealizar" la literatura» (Criado de Val, 1991: 7; en cursiva en el texto).
} 
teatro, como escritor y como empresario, pero ni la crítica ni el público supieron entender sus propuestas, lo que terminó desgastándole hasta tal punto que acabó su vida completamente desengañado de la literatura. Esto demuestra que hay cosas que escapan a la jurisdicción de la censura, cuyos argumentos no bastan para acabar con ellas, por mucho que se empeñen en moldearlas a su gusto. En estos casos, la represión de lo «anormal» ha de dejarse en manos de fuerzas mucho más poderosas y también más terminantes.

\section{Bibliografía}

Abellán, Manuel M. (1980): Censura y creación literaria en España (1939-1976). Barcelona, Península.

Alemany, Luis (1989): «Introducción» a Enrique Jardiel Poncela, La «tournée» de Dios. Madrid, Biblioteca Nueva, pp. 5-49.

CRIAdo De VAL, Isabel (1991): «De El movimiento V. P. a Pero... ¿hubo alguna vez once mil vírgenes?», Ínsula, 529, pp. 7-8.

DíAZ-PlAJA, Guillermo (1931): «Sexo y humor», La Gaceta Literaria, 100 (15 de febrero), p. 16.

ECO, Umberto (1984): «Los marcos de la “libertad” cómica», en Umberto Eco et al., ¡Carnaval! Trad. Mónica Mansour. México, FCE, 1989, pp. 9-20.

Foucault, Michel (1975): Vigilar y castigar. Trad. Aurelio Garzón del Camino. Barcelona, Círculo de Lectores, 1999.

GÓMEZ DE LA SERNA, Ramón (1930): «Humorismo», en Obras completas. Ed. de Ioana ZlOTESCU. Barcelona, Círculo de Lectores - Galaxia Gutenberg, 2005, vol. XVI, pp. 451-495.

(1958): «Enrique Jardiel Poncela», en Obras completas. Ed. de Ioana ZLOTESCU. Barcelona, Círculo de Lectores - Galaxia Gutenberg, 2004, vol. XVII, pp. 977-987.

GUBERN, Román (1981): La censura: función política y ordenamiento jurídico bajo el franquismo (1936-1975). Barcelona, Península.

JARDIEL PONCELA, Enrique (1932): La «tournée» de Dios. Madrid, Biblioteca Nueva. (1934): Tres comedias con un solo ensayo. Madrid, Biblioteca Nueva. (1950): «Carta sobre su estancia en Uruguay», en Obra inédita. Barcelona, AHR, 1967, pp. 233-240.

NEUSCHÄFER, Hans-Jörg (1991): Adiós a la España eterna. La dialéctica de la censura. Novela, teatro y cine bajo el franquismo. Trad. Rosa Pilar Blanco. Barcelona, Anthropos, 1994.

ORTEGA Y GASSET, José (1925): La deshumanización del arte, en La deshumanización del arte y otros ensayos de estética. Madrid, Revista de Occidente-Alianza, $3^{\text {a }}$ ed., 1984, pp. 11-54.

PÉREZ, Roberto (1990): «Introducción» a Enrique Jardiel Poncela, Amor se escribe sin hache. Madrid, Cátedra, pp. 11-65.

PuEO, Juan Carlos (2016): Como un motor de avión: biografía literaria de Enrique Jardiel Poncela. Madrid, Verbum. 